\title{
Women and intersectionality: perspectives based on digital fabrication as a viable platform for assistive design
}

\author{
Juliana Maria Moreira Soares \\ Universidade de São Paulo | Brasil | julianammsoares@usp.br \\ Paulo Eduardo Fonseca de Campos \\ Universidade de São Paulo | Brasil | pfonseca@usp.br
}

\begin{abstract}
This article aims to present analyzes and perceptions regarding the experience of a project developed under the following axes: women, disabilities and the development of Assistive Technology in spaces called Fablabs. The study is developed according to an exploratory approach, with a qualitative nature. This paper provides an introduction, an exploration of the experiments and the reflections over the performed activities. In the practical stages, among others, methods of an ethnographic nature and Design Research were used. The group of women, mothers of children with disabilities, variable in size during the practices (from two to five people), carried out activities to develop assistive technology products using digital manufacturing tools in a public laboratory of the Fablab Livre SP Network, in the city of São Paulo, Brazil. The reflections of this study go towards questions related to women's selfesteem in the face of processes of inclusion in the technological area. The multi-signification of the Fablab space and the need to expand the intersectional debate within these environments are also encounters provided by this research.
\end{abstract}

Keywords: Women; isability; fablabs; assistive technology; digital fabrication.

\section{INTRODUÇÃO}

Apesar do avanço dos mais diversos campos tecnológicos, a sociedade da informação permanece há muito tempo alicerçada sobre um complexo desafio, voltado à real democratização do acesso às múltiplas tecnologias por parte das minorias políticas, como populações de baixa renda, pessoas com deficiência e mulheres, sendo estes últimos os públicos protagonistas deste estudo. Trata-se de uma pauta multifacetada, podendo ser analisada sob diversos ângulos, indo do momento conceptivo desses projetos ao agenciamento humano sobre a tecnologia formalizada, estando todas essas fases conectadas e em convívio com as exclusões sistemáticas de tais setores sociais. Esses aspectos convocam a necessidade de reflexões através do reposicionamento das movimentações tecnológicas a favor destes grupos.

Os ambientes de produção tecnológica são espaços historicamente alijados da presença feminina e de outros grupos sociais, e que, não raramente, notabilizaram-se pela invisibilização do trabalho de mulheres que tiveram atuação nesse campo. Não são escassas as narrativas de apagamento a respeito das realizações protagonizadas por mulheres, as quais posteriormente foram vinculadas às figuras masculinas, como parceiros e colegas de trabalho. A pergunta "por que tão poucas?" (FAULKNER, 2001, p. 79) é um constante ponto de partida das mais diversas análises dentro dessa seara de estudos, do recorte filosófico ao enquadramento epistemológico do assunto. A representação simbólica do ser humano atrelado ao desenvolvimento de tecnologia e ciência ainda é do estereótipo do homem do jaleco branco de meia idade alienado em seu bastião, o hermético laboratório.

A partir desse olhar de produção tecnológica na sociedade, ressalta-se a forma como a manufatura digital vem ganhando relevo na contemporaneidade. Particularmente sob a forma de laboratório de fabricação digital mais comumente conhecido nos dias atuais como Fablab, sendo um desses espaços possíveis e cabíveis aos processos de desenvolvimento de tecnologia, cuja proposta inclusive excede o campo do capital privado e já integra o corpo de estratégias de política pública de certas cidades de grande porte.

Através de vivências e contextos imersivos em meio a públicos com deficiência físico-motora e suas cuidadoras (aqui, as figuras parentais) e em consideração às premissas anteriormente expostas, desenvolve-se o eixo propositivo deste estudo. Orientada por um contexto de escassez dentro no cenário de oferta de produtos da área de Tecnologia Assistiva (TA) no Brasil, formula-se a perspectiva de engajar grupos de mulheres relacionadas à temática da deficiência (aqui as mães de crianças com deficiência) dentro da área de tecnologia, usando como 
suporte a fabricação digital voltado ao desenvolvimento de objetos assistivos em conformidade com suas demandas cotidianas sinalizadas. A exploração das potencialidades e a observação das fragilidades a partir da imersão desses grupos em ambientes vocacionados à inovação e produção tecnológica, como são os Fablabs, é um dos objetivos desta pesquisa. A seguir, serão expostos os conceitos abarcados pelo presente estudo, de cunho exploratório e qualitativo, cujos resultados parciais obtidos foram extraídos a partir de abordagens que mesclam métodos etnográficos, da pesquisa narrativa e do Design Research.

\section{A TECNOLOGIA ASSISTIVA}

A área de conhecimento da Tecnologia Assistiva (TA) visa a desenvolver produtos e serviços voltados ao aumento da autonomia e independência da pessoa com deficiência (BERSCH, 2017). Ainda que em um patamar abaixo do necessário, dada a substancial parcela de brasileiros que convive com alguma espécie de deficiência no país - cerca de $23,9 \%$ da população, ou aproximadamente 45 milhões de indivíduos (IBGE, 2012) - o campo vive um período de crescente no país. Segundo o último Censo Demográfico realizado no país no ano de 2010 , mais da metade desse montante é constituída por mulheres e um total de 7,5\% são crianças $^{1}$ (IBGE, 2012). Um fenômeno detectado nesse panorama da pessoa com deficiência e relevante à pesquisa é a ocorrência do abandono parental ou do mínimo envolvimento com a criança com deficiência por parte da figura do pai (LAMB, BILLINGS, 1996; VENDRUSCULO, 2014), transformando a mãe em chefe de família e principal cuidadora de seu filho com deficiência, em muitos casos.

Os números expressivos convocam uma necessidade de amadurecimento das propostas nesse campo e tal movimentação tende a ganhar algum corpo a partir do reconhecimento e visibilidade das agendas voltadas às pessoas com deficiência na sociedade. Observa-se que a produção de TA recebe espaço em distintos locais difusores de conhecimentos, como em congressos multidisciplinares e em editais de financiamento público para o desenvolvimento de soluções na área. Nessa esteira, crescem as pesquisas e publicações científicas dedicadas ao campo nos últimos anos. É necessário pontuar que a eficácia da adoção desses equipamentos está diretamente atrelada à construção de políticas afirmativas e outras iniciativas conjuntas na área de inclusão social, afastando-se este estudo da pura visão tecnicista da tecnologia e assim compreendendo o campo assistivo como um possível aliado à diminuição da histórica distorção social, e não como um fim.

\section{OS FABLABS}

Os Fablabs ${ }^{2}$ são os ambientes que proporcionaram a interface prática desta pesquisa, conectando o desenvolvimento de Tecnologias Assistivas com as máquinas de fabricação digital - essa forma de produção feita com equipamentos do tipo Comando Numérico Computadorizado (CNC) à partir de um arquivo digital. Dessa forma, situando historicamente a emergência

${ }^{1} \mathrm{O}$ último censo do Instituto Brasileiro de Geografia e Estatística considera como crianças indivíduos de até 14 anos de idade (IBGE, 2012). desses locais, considera-se que os Fablabs têm sua origem nos Estados Unidos, através da experiência do professor Neil Gershenfeld no Media Lab, dentro do Massachussets Institute of Technology (MIT). A disciplina conectada à emergência desde modelo de espaço é lecionada por Neil desde o ano de 1998, levando o nome de How To Make (almost) Anything ${ }^{3}$. A cadeira busca a exploração da criatividade através da criação de projetos com os equipamentos presentes no laboratório, tendo seguido caminho ao encontro da apropriação das ferramentas de fabricação digital com a entrada dos anos 2000 e crescente popularização dessas máquinas. O conceito de Fablab que é atualmente difundido nasce desse local que visa a tradução da linguagem tecnológica de ponta em possibilidades de tangibilização de projetos em curtos e médios prazos, com viéses educacionais, inovadores e empreendedores (GERSHENFELD, 2012).

Oficialmente, os Fablabs se integram a uma rede mundial de laboratórios gerida pela Fab Foundation, havendo um total atual de aproximadamente 1750 espaços pelo mundo, filiados à rede liderada pelo Center For Bits and Atoms (CBA) do MIT. Através do cumprimento de uma série de requisitos e condições, um espaço de fabricação digital de qualquer parte do mundo pode se vincular à rede. Assim, a nomenclatura formal Fablab dada a um espaço estaria vinculada a tal filiação, a princípio. Porém, por essa associação se tratar de uma condição opcional, são muitos os ambientes os quais não se conectam à fundação. O espaço utilizado para o desenvolvimento da base empírica desta pesquisa integra a Rede Fablab Livre SP, inaugurado em dezembro do ano de 2015.

A implementação da Rede Fablab Livre SP está inserida dentro de um escopo de políticas públicas do município de São Paulo, Brasil. Disponibilizar a tecnologia às práticas de cunho social, alavancando conjuntamente as ações da esfera do microempreendedorismo e inovação foram algumas das perspectivas buscadas através da criação do projeto. São sinalizados resultados positivos até o momento, os quais envolvem a territorialização da tecnologia com base em produção de conhecimentos, viabilizados através de diálogos transversais entre os saberes das comunidades locais e as estruturas técnicas desses ambientes, incluindo projetos na área de Tecnologia Assistiva. Atualmente, são doze os laboratórios participantes, constituindo-se em espaços de usufruto público, gratuito e partidários do uso de softwares livres (CHIOVETTI, 2017). Tendo em vista esses aspectos de abertura e vocação social dos espaços, as unidades da rede foram os locais escolhidos para a realização das fases experimentais da presente pesquisa.

\section{AS ETAPAS EXPERIMENTAIS}

Neste estudo, busca-se trazer resultados parciais provenientes das atividades imersivas com o público protagonista dentro de um espaço Fablab. O grupo de mães foi integrado à pesquisa a partir do contato com uma organização não-governamental (ONG) da cidade de São Paulo, Brasil, a qual trabalha com atividades socioesportivas junto às crianças com deficiência. Essas

${ }^{2} \mathrm{O}$ termo Fablab surge dos sufixos das palavras fabrication laboratory (laboratório de fabricação).

${ }^{3}$ Em português, "Como fazer (quase) Tudo". 
intervenções ocorrem uma vez por semana e as tutoras ${ }^{4}$ das crianças desenvolvem práticas formativas ou de lazer enquanto as crianças participam das ações recreativas. As primeiras atividades empreendidas focaram a criação de vínculos com o grupo de mães e ocorreram nos ambientes da própria ONG. A presença constante da pesquisadora nas vivências sociais do grupo, a aplicação de dinâmicas grupais, questionários e conversas com grupos reduzidos foram ferramentas utilizadas derivadas da etnografia para realizar estas imersões.

Após esse primeiro momento, foram localizadas as mães com interesse em integrar o grupo de trabalhos práticos no laboratórios. Essas atividades, inicialmente, ocorreram em uma unidade da Rede FabLab Livre SP localizada próxima a uma estação de metrô. A opção por esse local foi negociada entre as partes envolvidas (as mães, a rede e a pesquisadora), através da exposição das possibilidades. Nesse sentido, as ferramentas de comunicação instantânea foram essenciais ao rápido contato e troca de informações com o grupo, tendo sido criado um grupo específico com esta finalidade em um aplicativo.

O grupo inicial era formado por cinco mulheres e foi reduzido ao número de duas mães ao final das etapas contempladas pela presente descrição. A priori, as mães foram convidadas para conhecerem o espaço do laboratório e iniciarem a familiarização com aquele ambiente, tão desvinculado de suas realidades. Para esse momento de geração de identificação, foi feito um convite à Amélia de Sousa para fazer uma apresentação ao grupo de mulheres (Figura 1). Amélia é usuária do espaço, sendo uma mulher com deficiência que desenvolve tecnologias assistivas para si e para sua comunidade através da fabricação digital, além de criar objetos também para outras utilizações. É moradora da região periférica da cidade de São Paulo, assim como grande parte das mães participantes da atividade. A fala com Amélia foi permeada por intercâmbios com as mães, as quais traziam relatos pessoais e elementos de reconhecimento com as histórias contadas. Conectar Amélia ao grupo significou ventilar possibilidades práticas e criar um referencial às mães, conforme foi reverberado e relatado posteriormente. Suscitar comunicações e trocas a respeito das atividades nos momentos seguintes a elas (como no próprio local, nos ambientes virtuais de contato ou na ONG), desenvolveuse como um mecanismo de captar esse olhar das mães sobre 0 andamento das ações.

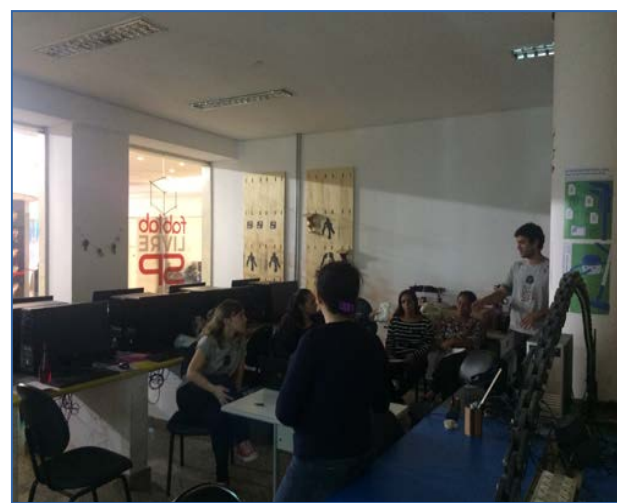

Figura 1: Amélia durante o bate-papo com as mães. Fonte: Autores.

A análise extensa do aparato metodológico empregado não é o foco deste estudo, mas sim as percepções iniciais sobre as incursões das mulheres no Fablab. Assim, aqui serão apresentados de maneira simplificada os métodos de imersão do público-protagonista no tema. Primeiramente, houve essa fase de tomada de familiaridade e vínculos com o espaço, descrita anteriormente. Em seguida, foram desenhados os critérios norteadores para o prosseguimento do ciclo, que buscou criar aproximação da linguagem de desenvolvimento de produtos junto às ferramentas de fabricação digital com as mães. Dessa forma, iniciou-se o processo de compreensão movido a partir da centralidade da seguinte questão: o que é desenvolver um produto? Foram incorporados recursos de ensino já utilizados na rede pública em seus cursos enxutos, além da consideração dos saberes empíricos e tácitos das mães, abraçados como essenciais amplificadores ao ciclo de aprendizado. Desta forma, a Figura 2 traz uma composição resumida dos aspectos desse processo:

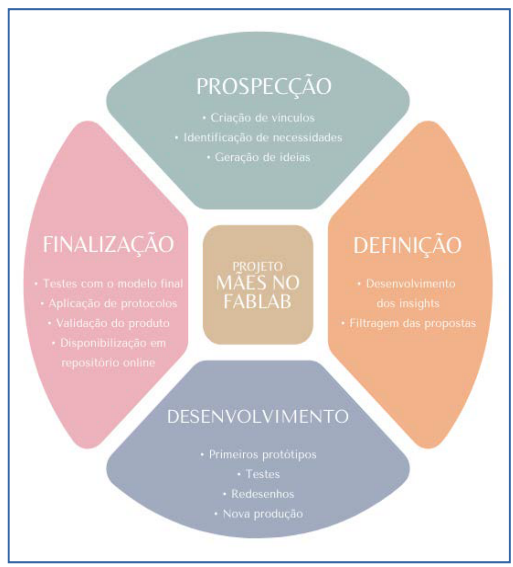

Figura 2: Ciclo proposto para a realização das atividades de desenvolvimento de tecnologias assistivas com o grupo de mães. Fonte: Autores.
${ }^{4}$ Apesar da abertura para homens e mulheres, à época somente mulheres e em grande parte mães participavam do projeto. 
Nas primeiras dinâmicas, ainda na ONG, foi orientada uma simples formulação do produto assistivo a ser desenvolvido pelas mães em laboratório, que se traduziu em descrever de forma sucinta a ideia no papel. Nesse momento, a partir da apresentação da tecnologia de produção a ser empregada no processo, aspectos de autoestima já se elucidavam como uma das principais pautas a serem trabalhadas com o grupo, sendo acolhidas e descritas em uma ferramenta de "caderno de bordo" da pesquisadora, além da geração de registros em gravações de áudio autorizadas pelo grupo. Constantes foram os relatos a respeito da possível dificuldade de enfrentamento com o tema da tecnologia. Apesar desse temor, observouse que insights e propostas de aprimoramentos ao projeto inicial surgiam em múltiplas situações. Designs e sugestões projetuais eram enviadas pelas redes de contato ou verbalizadas nos momentos de vivência. $\mathrm{O}$ imaginário sobre a aparente possibilidade construtiva infinita oferecida pelas máquinas, aliadas à curiosidade das mães com os equipamentos, resultava em um entusiasmado leque de ideias em emergência - em uma exposição inicial, uma das mães chegou a perguntar em tom de brincadeira, levando o grupo ao riso: "posso imprimir mais um filho então?". Dessa forma, movemo-nos para o primeiro tópico de centralidade desta exposição, relacionado à autoestima do grupo.

\section{A PAUTA DA AUTOESTIMA}

Antes, é necessário ressaltar que aqui entendemos a mãe da criança com deficiência como uma pessoa que compartilha a experiência vivida por essa população. 0 papel das cuidadoras, invisibilizadas até certo ponto da trajetória dos estudos da deficiência, foi trazido à esteira das análises através do olhar de teóricas feministas sobre a área (DINIZ, 2003). Ao incorporar as subjetividades vividas pelas cuidadoras nesse processo, compreende-se o caráter essencial das figuras de cuidado à vivência de muitos indivíduos com deficiência, quase indissociável à existência de pessoas com determinados graus de dependência e crianças.

Ao cruzar por campos relacionados à temática da fabricação digital, da sociologia e dos estudos da deficiência, Hurley (2018) traz a ideia do "outro" como um elemento constante na construção da narrativa da pessoa com deficiência. Esta posição à margem pode surgir a partir de uma sistemática exclusão social, culminando em estigmatização e em seu questionamento da capacidade de protagonismo. Em especial em processos onde não há uma especial adesão anterior dos atores com a temática, como a não identificação inicial dessas mulheres com a tecnologia, tais aspectos se tornavam bastante evidentes, porém, ainda em paralelo ao desejo individual de ganho de novos aprendizados atrelado ao desenvolvimento de propostas que visem a melhoria da qualidade de vida das crianças envolvidas.

Reconhecer o desafio de caminhar na contramão em apenas mais um dos roteiros do cotidiano, então, comunicava-se como um motor impulsionador da participação das mulheres nas oficinas. Desde o início ficou clara a necessidade do desenvolvimento de estratégias que potencializassem essas características ante tais dificuldades e que gerassem motivação e aderência do grupo às atividades. $A$ incorporação de etapas de prototipagem de baixa fidelidade, enfatizando as habilidades manuais e os saberes ligados ao artesanal, presentes no corpo de experiência das mães, e o estímulo à contribuição ao projeto das colegas em rodas de conversa durante os fazeres, gerando um espaço polissêmico de construção e reconhecimento ativos entre as partes, foram ações de potencial engajador neste campo. Uma oficina de integração de curta duração também foi realizada com esse objetivo, sendo conduzida em um espaço já familiarizado pelas mães (um dos locais de atividades da ONG). A atividade foi mediada pela equipe do Fablab, que levou recursos produzidos através da cortadora à laser destinados à confecção de bijuterias pelas mãos das mães, como pingentes e brincos (Figura 3 e 4).
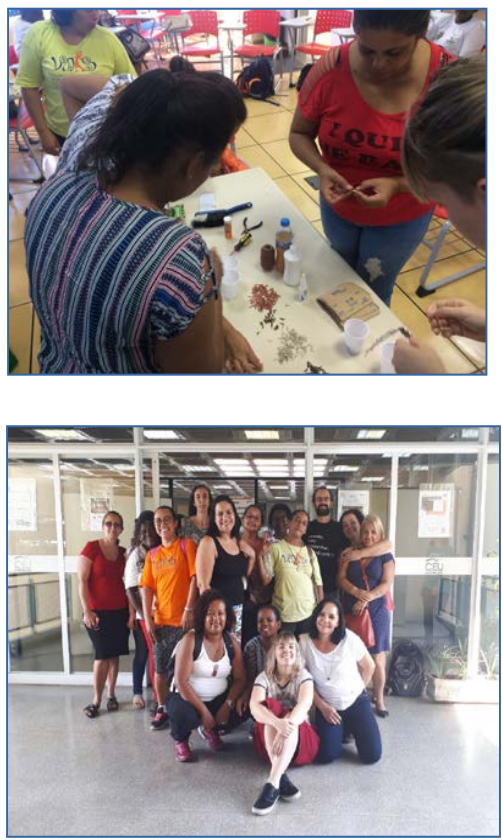

Figura 3 e 4: Momentos da oficina conduzida pela rede Fablab em um dos ambientes da ONG. Fonte: Autores.

\section{DIFICULDADE COM A TECNOLOGIA}

Softwares de modelagem, por mais intuitivos que sejam em suas arquiteturas, não são considerados programas de curta curva de aprendizado de maneira geral. Suas linguagens são distanciadas da maior parte das atividades cotidianas, sendo desafiadoras mesmo para usuários já familiarizados com ambientes computacionais. Na rede Fablab Livre SP, há o uso do Tinkercad, um software online e livre bastante simplificado, o qual serviu de plataforma virtual aos projetos nos encontros com o grupo. A partir do segundo encontro no espaço, as mães adentraram no ambiente da informática, aprendendo os fundamentos desse programa, visando a materialização da primeira peça-teste tridimensional, um pequenino cubo feito em material PLA na impressora 3D. As máquinas com seus ruídos ambientavam o local trabalhando em outras impressões, enquanto o grupo modelava as peças nos computadores - a presença das impressoras em ação era alvo de constante curiosidade do grupo e também uma mostra ilustrativa do processo.

Apesar do engajamento grupal e da conclusão desta tarefa proposta, uma série de dificuldades foram constatadas através dos relatos surgidos no curso das atividades e após esses momentos. Uma das mães relatou não ter 
contato frequente com computadores pelo fato de não ter um em casa. O "se encontrar" dentro do ambiente tridimensional nas telas, a quantidade de recursos oferecidos pelo software e problemas em manter as proporções desenhando através do mouse foram mais algumas das questões encontradas. "Em alguma hora eu até achei que seria fácil, mas é bem 'complicadinho' esse negócio, tem muitas possibilidades", comentou uma das participantes (Figura 5). Mesmo com o emblemático mote do movimento maker a respeito das diversões e contagiantes práticas envolvidas nesses processos, esse fundamental passo compreendido entre a formulação analógica do projeto e sua materialização nas máquinas de fabricação digital envolve uma complexa e morosa linguagem que pouco se assemelha na prática a uma atmosfera empolgante amplamente divulgada (NEMORIN, 2016).



Figura 5: As mães e um dos técnicos do local que auxiliou esta atividade. Fonte: Autores.

O encorajamento dado às comunidades iniciantes nas práticas de produção de tecnologias assistivas através da fabricação digital se relaciona com uma série de fatores facilitadores. Sendo reconhecida a dificuldade na apropriação dessa linguagem de modelagem, a utilização de modelos pré-existentes encontrados em repositórios online (a exemplo do Thingverse) se habilita como um alavancador do processo (BUEHLER, KANE, HURST, 2014). Esse tipo de abordagem foi utilizada nos encontros posteriores ao inicial, quando uma das mães, Rose Rodrigues, iniciou o desenho de um suporte para tablet acoplável à cadeira de rodas de seu filho. O modelo que serviu de base foi encontrado em um banco online, intermediando positivamente assim esta etapa de projeto.

Apesar das barreiras citadas, o engajamento das mães com o projeto se assentava sobre os horizontes já citados, de aprendizado e das trocas proporcionadas pela atividades, junto à perspectiva de desenvolverem seus projetos de produtos assistivos. Altas taxas de abandono desses recursos são relatadas (COSTA et al., 2015) e durante as vivências esse panorama era reforçado, de acordo com o registro de verbalizações do grupo. Por variados momentos, nem mesmo 0 acesso aos equipamentos é propiciado (devido à falta de oferta no mercado, de políticas públicas de oferta dos produtos ou de renda suficiente para obtenção do mesmo).

Entre as inúmeras questões relacionadas a tais situações, como processos de seleção, prescrição e orientação ao uso dessas TAs, levanta-se a problematização relacionada ao seu contexto de desenvolvimento (COSTA et al., 2015). Apesar de soar óbvio, ainda é necessário frisar que incorporar o maior número possível de usuários finais de um produto (neste caso, como cuidadoras, cuidadores e as próprias pessoas com deficiência) desde o início da curva de desenvolvimento desses processos se articula como uma estratégia de aumento das oportunidades de criação de uma linguagem mais assimilável e com maior atribuição de significados aos seus consumidores (KINTSCH, DEPAULA, 2002). Assim, distanciando-se de uma exaltação de práticas neoliberais baseadas em um movimento técnico, aqui se manifesta essa atribuição crítica às práticas industriais voltadas às soluções assistivas e se aponta para as possibilidades vistas pelas mães como valorosas dentro da área de fabricação digital. Ao visualizar a proximidade entre criadoras (elas, as mães, e seus filhos) e criação (os objetos assistivos) através dessas máquinas, o grupo demonstrou interesse $e$ expectativa no exercício de confecção de recursos assistivos mais adequados às suas demandas.

Buehler, Kane e Hurst (2014) ainda enfatizam que o tempo para se dedicar à apropriação das linguagens envolvidas nos processos de fabricação digital tende a ser considerável. Decerto, o reconhecimento da complexidade desse processo é um passo fundamental para o êxito das atividades. Ao eleger a realidade das mulheres do grupo como unidade de análise, sendo essas mães de crianças com deficiência, as quais vocacionam parte de sua rotina à atenção integral de seus filhos, constatou-se uma inconstância na presença desse grupo nos ambientes de aprendizado (os Fablabs), devido ao condicionamento de suas rotinas às agendas de seus filhos - bem como pela distância de seus domicílios até os laboratórios. Longe de entendermos isso como uma restrição, tal situação pode ser encarada como uma condição ao processo dialógico a ser estabelecido entre o espaço, o ciclo de aprendizado e as mães, compreendendo as possibilidades e todas as restrições existentes no perfil dessa comunidade. Se por um lado o domínio pleno no uso desses programas conferiria uma autonomia projetual às mães, por outro, assumir a possibilidade de uma longa jornada diluída em encontros menores para o uso dessas ferramenta sob a orientação dos técnicos dos espaços também é uma forma valiosa de trabalho que não traria dano aos objetivos-fim das atividades.

\section{REENCONTRO COM A TECNOLOGIA}

Profundamente conectado com o tema da autoestima, é comum que a vida de mães de crianças com deficiência se volte aos filhos de maneira ampla, deixando pouco espaço para as próprias subjetividades (GUERRA et al., 2015). Em contextos nos quais grande parte das mulheres envolvidas abandonou suas profissões em prol dos cuidados de seus filhos, reencontrar-se com estas modalidades criativas significou reacender certa percepção utilitarista perante a oportunidade de aprendizado, bem como a valorização de suas subjetividades. Com o andar das atividades, uma das participantes comentava com frequência sobre esse aspecto, de "movimentar a cabeça e se sentir útil" naquele espaço do Fablab, chegando a relacionar sua motivação à inscrição para um exame de vestibular do curso de design digital à época das atividades no laboratório. Os relatos também iam ao encontro de lembranças e aspectos afetivos, como das profissões antigamente performadas pelas mulheres.

Nessa linha, esta mãe também comentou que havia trabalhado em uma empresa de malhas, onde teve contato com processos têxteis que em muito a lembravam o 
trabalho de vetorização das imagens para serem enviadas ao corte na máquina a laser que à época fazíamos. Convocando as estruturas analíticas de Freud à Deleuze as suas reflexões, Sadie Plant (1995) remonta como a produção desse pensamento da computação se enraiza para além das primeiras programações realizadas por Ada Lovelace no século XIX, sendo possível ir ao encontro dessa memória quase ancestral reverberada em nesta participante ao se caminhar pelo tecido histórico do tema:

"O computador emerge da história da tecelagem, o processo tantas vezes dito ser a quintessência do trabalho das mulheres. $O$ tear é o site de vanguarda do software desenvolvimento. De fato, é do tear, ou melhor, do processo de tecelagem, que esse o papel toma outra sugestão. Talvez seja também um exemplo desse processo, para contos e textos são tecidos tão seguramente quanto fios e tecidos" (PLANT, 1995, p. 46).

Assim, o padrão tecnológico dos teares, máquina essa historicamente dominada pelas mãos de mulheres, serviu de profunda base à geração das primeiras máquinas analíticas ${ }^{5}$ e à primitiva ideia de codificação (PLANT, 1995) $\mathrm{E}$ com base nos relatos e observações das atividades, ao lado de significar um estranhamento e certo desconforto frutos deste comum lugar de expatriação das mulheres dessa área, esse fazer conectado a esse campo guarda potencial de reencontro com o entendimento das mães a respeito desse amplo conceito de tecnologia e de suas capacidades criativas perante a elas. Perceber a existência de cursos de programação e operação de máquinas a laser ao lado de oficinas de costura e de produção de formas para saboneteria, como há na programação dos Fablabs na rede, traz à tona essa significância a respeito de tecnologias nas quais parte das mães está bastante familiarizada, como as têxteis e outras tecnologias de trabalhos automatizados e do meio doméstico - mas que nem sempre são notadas como tecnologias, com base em um histórico processo de distorção e desvalorização dos fazeres tecnológicos destes loci.

\section{DEBATE COM O ESPAÇO PÚBLICO}

A inteligência coletiva seria uma importante coordenação de múltiplas competências entre as partes, a qual conduziria a um processo de mobilização de capacidades, segundo Lévy (2003). Assim, entender esses atributos, as brechas, as fragilidades e os sucessos das políticas aplicadas nesses espaços públicos, ainda mais considerando o caráter jovem desta iniciativa, é parte fundamental do percurso de estabelecimento e realinhamento de ações. A abertura ao debate é um dos recursos promotores de tal simbiose, propondo nesse dialogismo o foco em benefícios a ambos os lados - aos equipamentos públicos e as suas comunidades usuárias.

${ }^{5}$ Ada Lovelace (1815-1852) é considerada a primeira programadora ao lançar notas em um artigo contendo ideias a respeito de padrões algorítmicos sobre o equipamento conhecido como Máquina Analítica, de Charles Babbage, no qual também participou do projeto (PLANT, 1995).

${ }^{6}$ O Emprego Apoiado é uma metodologia estadunidense que se desenvolve a partir de um conjunto de ações voltadas à preparação e inserção no mercado de trabalho por parte da pessoa com deficiência e em outras condições de vulnerabilidade, sempre orientada por acompanhamento especializado. O ITS Brasil realiza práticas dentro desta linha em seus projetos, como na Rede Fablab Livre SP (ITS BRASIL, s/d).
Pederson (2016) reivindica uma maior postura inclusiva dos espaços maker atuais, ao examinar experiências artísticas feministas nesses sítios. Buehler et al. (2015) discutem a falta de representatividade das pessoas com deficiência nesse âmbito da fabricação digital, especificamente abordando os processos de produção de TA. Nessa linha, a rede Fablab já opera com uma série de ações afirmativas com interface direta com demandas da sociedade, a exemplo da prática do Emprego Apoiado ${ }^{6} \mathrm{e}$ de atividades aplicadas à perspectiva de gênero ${ }^{7}$, porém a presença ativa das mães com suas especificidades naquele ambiente significou situar o olhar a partir de um ponto de vista distinto, até então. Fazer desse paradoxo de distanciamento um vetor ao crescimento mútuo é um caminho de construção de novas formas de estruturação para o fortalecimento das práticas com grupos de vulnerabilidade ${ }^{8}$, como esse das mães.

O diálogo com os coordenadores e técnicos resultou em apoio e na fluidez da realização das atividades, porém, demandas que transcendiam o poder resolutivo local jogam luz para a necessidade de expansão do alcance das ações da rede (e em rede). Um exemplo dessa situação era a questão do transporte das mães com seus filhos, um fator de complexidade devido à mobilidade reduzida de parte das crianças, aliado à imprescindível necessidade de tomada de transporte público para o acesso aos espaços. A ideia inicial de trazer os filhos ao laboratório (promovendo uma integração necessária à experiência de desenvolvimento dos produtos) ocorreu somente uma vez. Houve tentativas de negociação entre as partes com a Secretaria da Municipal da Pessoa com Deficiência para a obtenção de transporte especial ${ }^{9}$, nas quais não se obteve sucesso.

Schienbinger (2001) apresenta como a perspectiva da entrada de pesquisadoras nas distintas áreas de estudos (como a medicina e a primatologia) contribuiu com achados que iriam mudar tais campos profundamente conhecimentos esses gerados a partir de uma perspectiva vivencial do outro, no caso, de outros corpos e histórias distintas das hegemônicas até então. Acima de tudo, trazer a essa composição a ideia de uma infraestrutura alicerçada nos saberes situados também em outros corpos, nesse caso, de mulheres que são mães de crianças com deficiência e moradoras de regiões periféricas, é uma provocação sobre a possibilidade de elaboração de novos fronts. Nesse sentido, pensar as tecnologias e os espaços a partir de entendimentos transversais, convocando os potenciais projetados nestas experiências corporais dessas pessoas, traz uma perspectiva nova de construção e consumo de conhecimentos dentro de um espaço público, mais vocacionado à acomodação de um maior número de diversidades possíveis.

${ }^{7}$ A rede promove oficinas voltadas à inscrição do público que se identifica como mulher, como workshops de marcenaria e programação.

${ }^{8}$ O Fablab acolhe grupos em situação de vulnerabilidade social para a realização de projetos, porém este projeto específico do grupos de mães de crianças com deficiência foi pioneiro para o espaço.

${ }^{9}$ Segundo as troca de informações, o transporte especial municipal somente é liberado para atividades não relacionadas com a área de saúde aos finais de semana. Como esta situação de finais de semana não era possível às mães, o transporte não fora liberado para as atividades nos Fablabs, que ocorriam entre terças e quintas-feiras. 


\section{O CAMINHO VALENDO MAIS DO QUE A CHEGADA}

Uma das percepções que mais se destaca ao final das etapas aqui abarcadas e quase se figura como um resumo a respeito das anteriores colocações, estabelece-se sobre a validade dos caminhos empreendidos ou do processo de travessia, mais que do resultado em si. Agustini (2014), ao comentar sobre a complexidade de se criarem conceitos e nomenclaturas sobre os formatos de laboratórios (como makerspaces, fablabs e hackerspaces), postula que há um atributo capaz de ser comum a todos esses, que é a experimentação. São muitos os autores que seguem nessa esteira de significação dessas práticas, como Dougherty (2013), que traz a ideia dessa movimentação como um "jogo experimental". Para além de locais que abrigam séries de maquinários, são espaços que devem ser reconhecidos pelas comunidades, processos e redes que o integram (AGUSTINI, 2014). Isso é essencial para início desse tópico final de análise sobre a experiência vivida com as mães nestes ambientes da Rede Fablab Livre SP.

Estar nos laboratórios era perceber como as diferentes comunidades se enveredavam por entre os equipamentos com suas experiências e intensidade de trocas. Muito embora essa consideração a respeito da vocação social desses espaços seja registrada em outras publicações da área, importou-se aqui o tipo de público envolvido no projeto, não situado em nenhum outro relato desse campo em âmbito nacional. Para essa comunidade de mães, os encontros soavam ter um considerável caráter de socialização, onde havia compartilhamento de suas vivências da semana (ou da quinzena), relatando seus eventos pessoais e de suas famílias. Tudo isso, ao lado dos movimentos de desenvolvimento dos produtos, que incluíam cooperação entre os projetos e experimentação de processos em materiais múltiplos, englobando pequenas jornadas de descobertas. O valor social do espaço, antes um desconhecido até então ao grupo, acena para uma das grandes potências desses ambientes, em especial quando se fala da rede paulistana.

As unidades da rede estão presentes em regiões periféricas de São Paulo, onde comumente é mais escassa a oferta de equipamentos públicos. Amélia conheceu o laboratório onde iniciou suas incursões na fabricação digital por estar próximo a sua região de domícilio, no qual o encontro com as possibilidades ali ofertadas colaborou com a superação de um estado de depressão. Conheceu pessoas e histórias, fez cursos e realizou projetos para conhecidos do bairro que necessitavam de recursos assistivos e outros aparatos. Essa territorialização das tecnologias em encontro com os saberes locais provoca então diversas significações para esses espaços, para além de sua aptidão ao material-experimental, desdobrando-se em locais de trocas múltiplas, de afetos e acolhimento.

\section{CONSIDERAÇÕES FINAIS}

Este artigo apresentou a experiência de um projeto desenvolvida sob os seguintes eixos: mulheres, deficiência e fabricação de Tecnologia Assistiva nos espaços Fablab. Os laboratórios utilizados fazem parte da Rede Fablab Livre SP, localizada na cidade de São Paulo, Brasil. Por meio de uma abordagem experimental sob um viés qualitativo de pesquisa, o estudo buscou trazer análises parciais a respeito dessa incursão realizada com um grupo de mães realizando atividades de desenvolvimento de produtos de Tecnologia Assistiva para seus filhos através da fabricação digital.

Entre as considerações, destaca-se a existência de quatro percepções iniciais a respeito da experiência. Apesar da expectativa e da força de vontade relacionada à vivência de desenvolver as tecnologias assistivas para seus filhos com suas próprias mãos, a questão da autoestima é diretamente entendida como um elemento fundamental a ser trabalhado em paralelo, junto a esse público pouco familiarizado com tais cenários tecnológicos. O reconhecimento da complexidade dessa linguagem é uma vertente importante às análises de projetos conduzidos nesse campo. Assim, a dificuldade com o tratamento de linguagens de tecnologia, conjugado ao fato de serem historicamente situadas fora das conjunturas do perfil das mulheres participantes, também se apresenta como um tópico fundamental relacionado ao sucesso ou à necessidade de redesenho das estratégias e estabelecimento de diálogos significativos entre as partes para o desenvolvimento desse tipo de projeto. Um reencontro com os conceitos tecnológicos e os aprendizados conectados com essa atmosfera é um terceiro ponto identificado pelos autores, como um elemento de engajamento do grupo com o processo.

Um penúltimo aspecto é coligado ao despertar da necessidade de maior contato e debate por parte de perfis diversificados com essa esfera de ações, visando a implementação de melhorias nas políticas locais e, assim, possibilitando a formação de um espaço cada vez mais inclusivo e consciente da pluralidade. $\mathrm{E}$, finalmente, a validade da experiência de travessia por esse processo imersivo dentro dos Fablabs da rede, entendendo o potencial transformador desses caminhos nas esferas individuais e comunitárias, despertando para a possibilidade de criação de novas redes colaborativas que podem emergir a partir deles nas comunidades. Como sugestões às futuras pesquisas, emerge a proposta de uma maior atenção a ser dedicada às pautas interseccionais dentro dos ambientes do tipo Fablab e no campo relacionado às práticas de fabricação digital em geral, assuntos ainda pouco explorados no país.

\section{NOTAS}

Esta pesquisa está aprovada no Comitê de Ética em Pesquisa (CEP - Plataforma Brasil), sob o CAAE 70080217.0.0000.5504.

\section{AGRADECIMENTOS}

Os pesquisadores agradecem a Coordenação de Aperfeiçoamento de Pessoal de Nível Superior (CAPES) pelo apoio financeiro à pesquisa.

\section{REFERÊNCIAS}

AGUSTINI, G. (2014). O momento dos laboratórios como espaço de criatividade, inovação e invenção. In: COSTA, E AGUSTINI, G. (Org.). De baixo para cima. Rio de Janeiro: Aeroplano.

BENEDETTO, I. L. C. (2011). Contribuições metodológicas para o desenvolvimento de produtos em tecnologia assistiva. 2011. 162 f. Dissertação (Mestrado em Design) - Escola e Engenharia, Faculdade de Arquitetura, Universidade Federal do Rio Grande do Sul, Porto Alegre.

BERSCH, R. (2017). Introdução à Tecnologia Assistiva. Porto Alegre: Assistiva - Tecnologia e Educação. 
BUEHLER, E.; KANE, S. K.; HURST, A. (2014). ABC and 3D: opportunities and obstacles to $3 D$ printing in special education environments. In: Proc. ASSETS'14, 2014, pp. 107-114.

BUEHLER, E. et al.et al. (2015). Sharing is caring: assistive technology designs on Thingiverse. In: 33rd Annual ACM Conference on Human Factors in Computing Systems. Proceedings... Seoul: Yonsei University, p. 525-534.

CHIOVETTI, S. P. (2017). Inovação nos Serviços Públicos na cidade de São Paulo (2013-2016). São Paulo: Fundação Perseu Abramo. 136 p.

COSTA, C. R. et al. (2015). Dispositivos de tecnologia assistiva: fatores relacionados ao abandono. Cad. Ter. Ocup. UFSCar, São Carlos, v. 23, n. 3, p. 611-624.

DINIZ, D. (2003). Modelo social da deficiência: a crítica feminista. Série Anis, v. 28, p. 1-8.

DOUGHERTY, D. (2013). The maker mindset. In: HONEY, M.; KANTER, D. E. (Eds.), Design/Make/Play. New York, NY: Routledge.

FAULKNER, W. (2001). The technology question in feminism: a view from feminist technology studies. Women's Studies International Forum, Vol. 24, No. 1, pp. 79-95.

GERSHENFELD. N. (2012). How to Make Almost Anything: The Digital Fabrication Revolution. Foreign Affairs, 91, n. 6, p. 43-57.

GUERRA, C. S. et al. (2015). Do sonho a realidade: vivência de mães de filhos com deficiência. Texto Contexto Enferm, Florianópolis, 24(2): 459-66.

HURLEY, U. (2018). "The Embodiment of Pure Thought"? Digital Fabrication, Disability, and New Possibilities for Auto|Biography, a/b: Auto/Biography Studies, 33:2, 285300 .

IBGE - Instituto Brasileiro de Geografia e Estatística. (2012). Censo Demográfico 2010. Resultados gerais da amostra. Rio de Janeiro: IBGE.
KINTSCH, A.; DEPAULA, R. (2002). A framewok for the adoption of assistive technology. In: Conference on Assistive Technologies, 5., 2002, Edinburgh. Proceedings... New York: ACM. 11 p.

NEMORIN, S. (2016). The Frustrations of Digital Fabrication: An Auto/Ethnographic Exploration of "3D Making in School". International Journal of Technology and Design Education 27.4, 517-35. Springer.

LAMB, M. E.; BILLINGS, L. A. L. (1996). Fathers of children with special needs. In: M. E. Lamb. (Org.). The role of the father in child development. London: John Wiley \& Sons. p. 179-190.

LÉVY, P. (2003). A inteligência coletiva: por uma antropologia do ciberespaço. 4a ed. São Paulo: Loyola.

PEDERSON, C. C. (2016). Situating Making in Contemporary Latin America Feminist Art. Journal of Peer Produciton. Issue \#8: Feminism and (un)hacking.

PLANT, S. (1995). The Future Looms: Weaving Women and Cybernetics. In: FEATHERSTONE, M.; BURROWS, R. (eds). Cyberspace/Cyberbodies/Cyberpunk. Cultures of Technological Embodiment. London: Sage Publications. p. 45-64.

SCHIENBINGER, L. (2001). O Feminismo Mudou a Ciência? Bauru/SP: EDUSC.

VENDRUSCULO, L. E. B. (2014). A descoberta da deficiência do filho: o luto e a elaboração dos pais. 2014, $34 \mathrm{f}$. Monografia (Bacharelado em Psicologia) Departamento de Humanidades e Educação, Universidade Regional do Noroeste do Estado do Rio Grande do Sul, ljuí.

WAJCMAN, J. (2004). Technofeminism. Cambridge, UK: Polity. 